\title{
The Valuation of Cryptocurrencies in Single-Asset and Multiple-Asset Models
}

\author{
Rebecca Abraham ${ }^{1}$, Zhi Tao ${ }^{2}$ \\ ${ }^{1}$ Finance and Economics, Nova Southeastern University, Fort Lauderdale, FL, USA \\ ${ }^{2}$ University of North Texas, Denton, TX, USA \\ Email: abraham@nova.edu,Zhi.Tao@unt.edu
}

How to cite this paper: Abraham, R. and Tao, Z. (2019) The Valuation of Cryptocurrencies in Single-Asset and MultipleAsset Models. Theoretical Economics Letters, 9, 1093-1113.

https://doi.org/10.4236/tel.2019.94071

Received: March 13, 2019

Accepted: April 26, 2019

Published: April 29, 2019

Copyright (c) 2019 by author(s) and Scientific Research Publishing Inc. This work is licensed under the Creative Commons Attribution International License (CC BY 4.0).

http://creativecommons.org/licenses/by/4.0/

(c) (i) Open Access

\begin{abstract}
Cryptocurrencies are virtual currencies employed in blockchain transactions. They are particularly worthy of theoretical examination, given the limited academic literature on the subject. This paper constructs valuation models of bitcoin and altcoins, both as single investments and components of mutliple-asset portfolios. As single investments, cryptocurrencies are valued at the confluence of Legendre utility functions, with Esscher transformed Geometric Levy pricing processes. As part of portfolios, cryptocurrencies are contained in traditional Markowitz portfolios which are varied by increasing the proportion of the riskless asset, shorting the risky asset, or adding currency options. Theoretical formulations show that Markowitz models combined with bitcoin, located on the Capital Market Line (which we term $C M L$ portfolios), have low returns, mainly due to the presence of the riskless asset. Such portfolios are appropriately suited to the investment goals of risk-averse traders, while overlooking the preferences of risk-takers. To satisfy less riskaverse investors, we propose a high-return portfolio with 9 asset choices, consisting of risky assets, cryptocurrencies, US dollars, soybean futures, Treasury bond futures, oil futures, currency options on the US dollar, currency options on the Mexican peso, and technology, or biotechnology stocks. Laplace transforms are employed to suppress volatility, skewness, or kurtosis of returns, which empirical studies have found to contribute to tail risk contained in outliers in fat-tailed distributions.
\end{abstract}

\section{Keywords}

Legendre Function, Esscher Transformation, Cryptocurrency, Bitcoin, Laplace

\section{Introduction}

Cryptocurrencies, led by bitcoin, are virtual currencies, used in transactions rec- 
orded on the blockchain, a global public ledger. The sentiment that the blockchain will have far-reaching disruptions, from global supply chains to shipping, has led to a surge in bitcoin prices. With a $168 \%$ increase in bitcoin prices from 2016-2017, reaching a peak of $\$ 2700$ in May, 2017, the market capitalization of funds flowing into cryptocurrencies rose from $\$ 25$ billion in April 2016-\$1000 billion in June, 2017 [1].

The blockchain is available to all computers with the bitcoin protocol, granting every user access to each transaction. A seller verifies that a buyer has the bitcoins associated with his or her address, then completes the sale, recording it in the public blockchain ledger. As an address cannot be linked to a user, the privacy of buyer and seller are maintained [2]. Unlike coins and paper currency, cryptocurrencies lack intrinsic value, meaning that they have no physical form. Their value is not supported by a government. The benefits of decentralization of authority are that it avoids the concentration of power that would permit a single user to control the system, or loss of resilience from the failure of the computer system at a central point [3]. Alternate cryptocurrencies to bitcoin, such as litecoin, with a faster hashtag function, peercoin, with superior verification, ether, with lower cost, and appcoins, which can be used as currencies have emerged, though bitcoin still dominates, with $93 \%$ market share [4].

The academic literature is sparse, with few studies evaluating the addition of bitcoin to portfolios. A notable exception is the [5] addition of bitcoin to a portfolio of stocks, bonds, foreign currencies, commodities, and real estate, using weekly 2010-2013 data. The addition of bitcoin significantly improved the mean return, while reducing the risk of the portfolio [5]. [4] supported this finding with their observation that bitcoin depreciated against the US dollar, while other currencies appreciated against it. They coined the term, reinforcement effect, whereby certain initiators of bitcoin trading are joined by others, resulting in new users flooding the market. There may be a substitution effect, with [4] observing some replacement of bitcoin by alternate currencies, after bitcoin's sharp decrease in prices, in October, 2013. This paper attempts to fill three gaps in the academic literature, 1) There is a need for valuation models for the leading cryptocurrencies, such as there are for stocks, bonds, and derivatives ([6] [7] [8]). 2) [9] observed informed trading in the bitcoin market in advance of large positive and negative events, suggesting that cryptocurrencies may be an investment choice for informed traders. We posit that such traders may differ in the extent of risk aversion. The microstructure literature suggests that, on the one hand, risk-taking informed traders initiate purchases of cryptocurrencies ([10]), while on the other, risk-averse informed traders sell information ([11]). We derive cryptocurrency valuation models for both types of traders, 3 ) There is a need for models that update traditional portfolio theory models of risk-free assets and risky assets ([12]). What is the effect on risk and return of a portfolio of risk-free assets and risky assets, if cryptocurrencies are added? Alternatively, could risk reduction be achieved by short selling risky assets? What would be the impact of adding foreign currencies to such a portfolio? We address all of these questions 
in our formulations of various portfolio models including cryptocurrency.

The remainder of this paper is organized as follows. Section 2 is a Review of Literature, Section 3 includes Single-Asset Cryptocurrency Portfolios, while Section 4, consists of Multiple-Asset Capital Market Line Portfolios. Section 5 describes the Conclusions.

\section{Review of Literature}

\subsection{Investor Demand for Cryptocurrencies}

The reinforcement effect consists of risk-taking informed traders, recognizing the future uses of cryptocurrencies, in reducing both a business's cost of goods sold, and its administrative expenses. Consider an importer. Currently, the firm will need to pay for foreign goods through bank loans, having to provide letters of credit to the foreign bank, along with verification documents. After the first transaction, all of these items may be stored on the blockchain, with cryptocurrencies being used to complete the transaction. All management of inventory and accounts receivable will occur on the blockchain, diminishing administrative expenses. Other businesses in the global supply chain, shipping, and retail, will benefit, leading to significant positive spillover economic effects. [4] predicted that this "winner-take-all," feature of bitcoin would lead to the network effect of attracting more and more investors. In the four quarters from May 2013-May 2014, they observed price increases of $143 \%$ - 400\% with increased demand for all cryptocurrencies. Positive correlations between bitcoin and six other cryptocurrencies provided further support for the reinforcement effect in Quarter 1 and Quarter 3, with some substitution of bitcoin by litecoin and peercoin, in Quarter 2 and Quarter 4.

By definition, informed traders capitalize on profit-making opportunities present in information events ([13]. As information about each cost-reducing application of the blockchain is disseminated, we theorize that informed traders increase their investment in cryptocurrencies, inflating prices. [14] surveyed network users, finding that they had higher expectations of future prices, based on large cryptocurrency purchases reported in social media, or newspaper articles. Informed trading in cryptocurrencies is similar to informed trading in the stock market, which has been examined in the literature. [15] proposed a model of informed trading in the stock market, wherein informed traders seek profits in anticipation of potential stock price increases (decreases), before positive (negative) earnings surprises, dividend announcements, and merger announcements. Informed traders arrive in a continuous auction, making large-sized trades at the lowest transaction costs ([16]). Trade prices rise on buy orders, falling on sell orders ([10] [17]). For example, cash mergers release positive signals, as acquirers are perceived as being cash-rich, in their ability to acquire target firms for cash. In contrast, stock mergers release negative signals, as acquirers are viewed as having to purchase target firms through exchanges of stock, due to limited availability of cash. Consequently, significant informed buying of 
call options on acquirer stock in cash mergers, along with significant informed purchase of put options on acquirer stock in stock mergers, have been observed ([18]). [11] theorized that informed traders differed in their attitudes towards risk aversion. Risk-taking informed traders actively trade on the basis of privileged information. For example, they may purchase stocks forecasted to exceed earnings expectations, the day before the earnings announcement, in anticipation of price increases the next day. In contrast, risk-averse informed traders prefer to forego trading fearing losses from momentary price changes. They may sell information by creating a mutual fund. The load on the fund permits the fund manager to charge for information that he or she provides to investors, including the investments selected by the fund manager for the client, and the optimal time to purchase.

The only examination of informed trading in the bitcoin market was undertaken by [9], who observed informed trading on both positive and negative signals. On positive signals, order sizes of informed buyer-initiated bitcoin orders were significantly higher than uninformed seller-initiated bitcoin orders. On negative signals, order sizes of informed seller-initiated bitcoin orders were significantly higher than buyer-initiated bitcoin orders.

\subsection{The Role of Cryptocurrencies in a Portfolio}

Single-Asset Investments. Successive empirical examinations of the determinants of bitcoin prices have established that prices are being fueled by expectations of future gain. For instance, [19] found that initial interest in cryptocurrency, as determined by Google Trends and Wikipedia search terms, using 2011-2013 data, increased price. These results were supported by [20]'s expanded 2009-2014 sample, in which Internet searches determined price, initially, in the short-term. The subsequent increased velocity of bitcoin usage, coupled with news about surges in bitcoin prices, stimulated further demand, significantly accelerating long-term price increases. [21] extended the above studies by including macroeconomic and financial variables, such as the Consumer Price Index, industrial production, real personal consumption expenditures, the S\&P 500 Index, the 10-year Treasury note, the euro exchange rate, and change in unemployment, in an assessment of predictors of bitcoin prices. Only the proxy of consumer expectations for future profitability, represented by the spread of daily high and low prices, was a significant predictor of bitcoin prices.

Multiple-Asset Investments. [12] introduced the concept of portfolio diversification, by specifying that an optimal portfolio, of risky corporate securities, and riskless government securities, will maximize returns with minimum risk. His minimum variance portfolio frontier, with return-risk combinations of portfolios that lay on the frontier, yielded optimal returns with the least risk. The addition of cryptocurrencies to such portfolios, elevates returns, while increasing volatility. To achieve risk-return optimality, [5] created a 13-asset portfolio, including global stocks, bonds, currencies, commodities, hedge funds, and real es- 
tate increasing returns with annualized returns of $36.11 \%$, though they were less successful in reducing risk. [22] returns outperformed an S \& P 500 portfolio, with less risk, as measured by volatility and skewness. Only the kurtosis measure of risk, was higher for the [22] time series momentum portfolio of stocks and bitcoins.

\section{Single Asset Cryptocurrency Portfolios}

Single-Asset Bitcoin Portfolios. Perceiving the risk-taking benefit of the blockchain, risk-taking informed traders invest in bitcoin, their lack of concern for risk being exemplified by the upward-sloping utility function, $O S$, in Figure 1, where the promise of profit potential encourages purchases of bitcoin. Risk-averse informed traders increase their investment as shown in the downward-sloping portion of the utility function, $F P$, as their risk aversion declines upon sale of information to a mutual fund. The utility function, OSFP, in the form of a harmonic wave, may be described by a Legendre function. In other words, the path of the random variable, $z$, that describes the beliefs of the risk-taking informed traders, is listed in the Legendre-based utility function in Equation (1) ([23]),

$$
\left(1-z^{2}\right) \cdot d^{2} w / d z^{2}-2 z d w / d z+\left[v(v+1)-\mu^{2} /\left(1-z^{2}\right)\right] w=0
$$

where, $\mu$ and $v$ are complex constants. The branch points of $z$ are at $F$ and $P$, where the direction of risk aversion changes. Figure 1 shows a single-asset investment in bitcoin, At $O$, the propensity for taking risk increases for the risk-taking informed trader, while at $F$, risk-taking propensity decreases for the risk-averse trader. The risk-averse trader, must be paid compensation, $X P$, for assuming the additional risk of the bitcoin investment.

We add a utility function that is equivalent to this compensation to Equation (1), as derived by [24],

$$
\begin{aligned}
& \left(1-z^{2}\right) \cdot d^{2} w / d z^{2}-2 z d w / d z+\left[v(v+1)-\mu^{2} /\left(1-z^{2}\right)\right] w \\
& +\left[m_{2} / 3 m_{1}-1\right] /\left[\theta^{2}-2 \theta+\left(\theta^{3}-3 \theta^{2}+3 \theta\right) m_{2} / 3 m_{1}\right]
\end{aligned}
$$

$m_{1}=$ coefficient of absolute risk aversion,

$m_{2}=$ change in coefficient of absolute risk aversion,

$\theta$ function $=$ profit function of investing in a risky gamble.

The risk-averse trader's acceptance of a risky bitcoin investment in a mutual fund is predicated upon his or her desire to avoid risk (risk aversion), decreasing more than the increase in profit potential, or $-\Delta\left[m_{2} / 3 m_{1}\right]>\Delta$ [the $\theta$ profit function].

The price function for bitcoin follows a martingale process, in that the next price is equal to the present observed value, which is unpredictable from past observations.

Figure 1 specifies the optimal price for single-asset bitcoin portfolios. OSFP is a Legendre utility function which intersects with the Martingale Measure, $A B$, to yield optimal prices. Risk-taking traders invest in rising cryptocurrency values, 
Risk-Taking Propensity

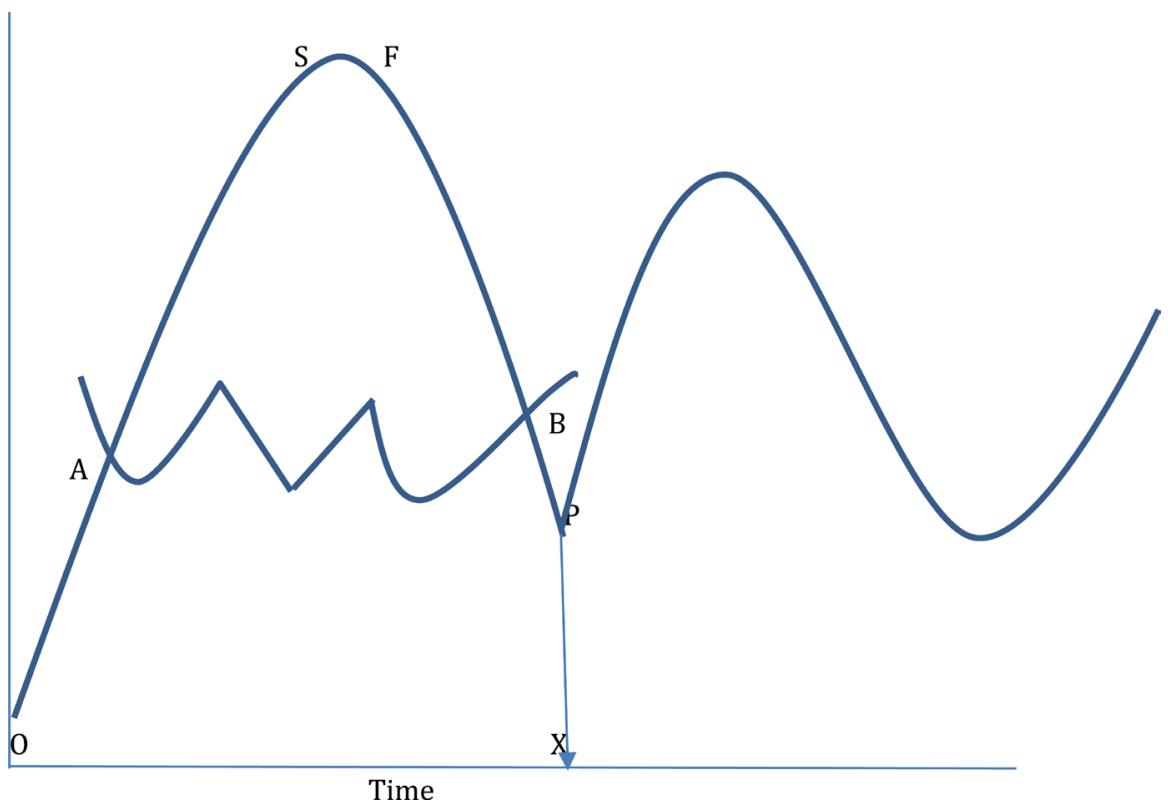

Source: This paper.

Figure 1. Optimal price for a single-asset bitcoin portfolio.

at $A$. Risk-averse traders purchase at bargain prices, at $B$, their compensation for additional risk being represented by $X P$.

With a completely unknown trajectory, bitcoin's prices may follow the Geometric Levy process, which is used for highly uncertain jump processes (See [25] for a review). The Esscher transformation is frequently used to represent collective risk ([26])), in which asset prices react to the investment by a number of investors whose actions are influenced by each other. Therefore, we present bitcoin's price distribution as an Esscher-Transformed Martingale Measure Geometric Levy process. If $S_{k}$ is the price of bitcoin at time period, $k$, the compound return on a bitcoin investment may be represented by $\Delta Z_{k}([27])$.

$$
\Delta Z_{k}=\log \left(S_{k} / S_{k-1}\right)
$$

[27] presents the return process as,

$$
\begin{aligned}
Z_{t}= & \sigma W_{t}+b+0.5 \sigma^{2}+t \int_{0}^{t} e^{x}-1-x_{1}(|x| \leq 1) x v d x \\
& +\int_{0}^{t} \int_{x<1}^{\infty}\left(e^{x}-1\right) N_{p} d s d x
\end{aligned}
$$

We remove the $W_{t}$ term, which represents a Weiner process based on a predictable continuous normal distribution. We retain the $N_{p}$, the discontinuous Poisson process with a function $x<1$, that describes small jumps.

$$
Z_{t}=b+0.5 \sigma^{2}+t \int_{0}^{t} e^{x}-1-x_{1}(|x| \leq 1) x v d x+\int_{0}^{t} \int_{x<1}^{\infty}\left(e^{x}-1\right) N_{p} d s d x
$$

Excessive volatility, measured by the variance, skewness, and kurtosis, of deviations of prices from mean bitcoin values, is overcome by adding a Laplace transform to Equation (5). The $\sigma^{2}$ term measuring volatility is absorbed by the 
Laplace transform, as follows, (see the $L$ term below),

$$
\begin{aligned}
Z_{t}= & b+0.5 \sigma^{2}+t \int_{0}^{t}\left(e^{x}-1-x_{1}(|x| \leq 1) x\right) v d x+\int_{0}^{t} \int_{x<1}^{\infty}\left(e^{x}-1\right) N_{p} d s d x \\
& +L\left[(x-\mu)^{2} / \sigma+(x-\mu)^{3} / \sigma+(x-\mu)^{4}\right] / \sigma
\end{aligned}
$$

The necessary condition for the maximum price is the second derivative of Equation (6),

$$
\begin{aligned}
& t\left(e^{x}-1-x_{1}(|x| \leq 1)(x)\right) v+\int_{0}^{t} \int_{x<1}^{\infty}\left(e^{x}-1\right) N_{p} \\
& +L^{\prime}\left[(x-\mu)^{2} / \sigma+(x-\mu)^{3} / \sigma+(x-\mu)^{4} / \sigma\right]=0
\end{aligned}
$$

The sufficient condition for the maximum price is the second derivative of Equation (6),

$$
\begin{aligned}
& t\left(e^{x}-x_{1}(|x| \leq 1)(x)\right) v+\left(e^{x}\right) N_{p}^{\prime} \\
& +L^{\prime \prime}\left[(x-\mu)^{2} / \sigma+(x-\mu)^{3} / \sigma+(x-\mu)^{4} / \sigma\right]=0
\end{aligned}
$$

Equation (8) must be equated to the second derivative of Equation (1) to obtain the maximum price for the risk-taking informed trader. The second derivative of Equation (1) is presented in Equation (9),

$$
2 d^{4} w / d z^{4}-2-\mu^{2}(1-2 z) d w / d z
$$

Setting $z=x$, and equating Equation (8) with Equation (9), yields an expression that may be used to obtain the optimal price, $x$, for the risk-taking informed trader,

$$
\begin{aligned}
& 2 d^{4} w / d x^{4}-2-\mu^{2}(1-2 x) d w / d x \\
& =t\left(e^{x}-x_{1}(|x| \leq 1)(x)\right) v+\left(e^{x}\right) N_{p}^{\prime} \\
& +L^{\prime \prime}\left[(x-\mu)^{2} / \sigma+(x-\mu)^{3} / \sigma+(x-\mu)^{4} / \sigma\right]
\end{aligned}
$$

For the risk-averse trader, we add the [24] function, to the left side of Equation (10). This function describes the probability of a risk-averse trader earning a profit with a high-risk gamble. It compensates for the acceptance of risk, that is excessively higher than the risk-averse trader's normal threshold for risk,

$$
\begin{aligned}
& 2 d^{4} w / d x^{4}-2-\mu^{2}(1-2 x) d w / d x \\
& +\left[m_{2} / 3 m_{1}-1\right] /\left[\theta^{2}-2 \theta+\left(\theta^{3}-3 \theta^{2}+3 \theta\right) m_{2} / 3 m_{1}\right] \\
& =t\left(e^{x}-x_{1}(|x| \leq 1)(x)\right) v+\left(e^{x}\right) N_{p}^{\prime} \\
& +L^{\prime \prime}\left[(x-\mu)^{2} / \sigma+(x-\mu)^{3} / \sigma+(x-\mu)^{4} / \sigma\right]
\end{aligned}
$$

Single-Asset Litecoin Portfolios. Litecoin processes a block every $2.5 \mathrm{mi}$ nutes, as opposed to bitcoin's slower 10-minute processing speed. However, it has never had bitcoin's popularity, presumably due to greater memory demands, and more expensive mining ([28]). Likewise, peercoin and the appcoins have the technical benefits of bitcoin, although bitcoin's first-mover status has given it market domination. The following price function for litecoin applies to both 
peercoin, and the appcoins. Let $L_{t}$ be the martingale measure for Geometric Levy processes, $f(s, x)$ and $g(s, x)([27])$.

$$
\begin{aligned}
L_{t}(f, g)= & \exp \left\{\int_{0}^{t} f_{s} d W_{s}-0.5 f_{s} d W_{s}-0.5 \int_{0}^{t} f^{2} s d s+\int_{0}^{t} g(s, x) N d s d x\right. \\
& \left.-\int_{0}^{t} \int_{x<1}^{\infty}\left[e^{g(s, x)}-1-g(s, x)\right] v d x d s\right\}
\end{aligned}
$$

We remove the Weiner process term, differentiating to yield the necessary condition for the maximum price,

$$
L_{t}^{\prime}(f, g)=0.5 f s d s+g(s, x) N d s d x-\int_{x<1}^{\infty}\left[e^{g(s, x)}-1-g(s, x)\right] v d x d s
$$

Differentiating Equation (13) to obtain the sufficient condition for price maximization,

$$
L_{t}^{\prime \prime}(f, g)=0.5 f^{\prime} s d s+g^{\prime}(s, x) N d s d x-\int_{x<1}^{\infty}\left[e^{g(s, x)}-1-g(s, x)\right] v d x d s
$$

Equating the second derivative of the utility function in Equation (9) and Equation (14), the risk-taking trader's optimal price is given by $x$ below,

$$
\begin{aligned}
& 2 d^{4} w / d x^{4}-2-\mu^{2}(1-2 x) d w / d x \\
& =0.5 f^{\prime} s d s+g^{\prime}(s, x) N d s d x-\int_{x<1}^{\infty}\left[e^{g(s, x)}-1-g(s, x)\right] v d x d s
\end{aligned}
$$

Given the lower volume of usage for litecoin, we assume that there is greater uncertainty associated with adding it to a portfolio. This increased risk may not affect the risk-taking trader, so that the utility function specified in Equation (1), will remain unchanged. However, the risk-averse trader will demand higher compensation. The compensation will differ from that obtained in Equation (2). With greater risk, the risk-averse investor may demand a definite dollar amount of compensation, termed $Y$. Since litecoin is less well-known than bitcoin, investor expectations may be satisfied if the optimal least favorable Minimal Distance Martingale Measure for a Geometric Levy process is obtained. Esscher transformations cannot be used, as the low volume of investment in litecoin suggests that fewer risk-averse traders are engaging in collective action. For the risk-averse trader, the second derivative of the utility function in Equation (11) is equated to the price function in Equation (14), with the compensation, $Y$, included on the left side,

$$
\begin{aligned}
& 2 d^{4} w / d x^{4}-2-\mu^{2}(1-2 x) d w / d x \\
& +\left[m_{2} / 3 m_{1}-1\right] /\left[\theta^{2}-2 \theta+\left(\theta^{3}-3 \theta^{2}+3 \theta\right) m_{2} / 3 m_{1}\right]+Y \\
& =0.5 f^{\prime} s d s+g^{\prime}(s, x) N d s d x-\left[e^{g(s, x)}-1-g(s, x)\right] v d x d s
\end{aligned}
$$

Single-Asset Ether Portfolio. Ether's strength lies in its low transaction fee, which was \$ 0.33 , compared to $\$ 23.00$, for bitcoin ([29]). Both the risk-taking trader, and the risk-averse trader, would obtain significant cost savings, by substituting ether for bitcoin. In Figure 2, the risk-taking trader's utility function is based upon the relative risk aversion of bitcoin in relation to ether. The investor will desire ether more than bitcoin, if the slope of relative risk aversion to bitcoin, 
represented by $O S$, is steeper than the slope of relative risk aversion relative to ether, $P Q$. We define $m_{3}$, as the coefficient of relative risk aversion for bitcoin due to preference for ether, and $m_{4}$, the change in relative risk aversion for bitcoin due to preference for ether. If ether investments become more attractive than bitcoin,, $m_{3}$ and $m_{4}$ will be positive.. Conversely, if ether investments become less attractive with respect to bitcoin, $m_{3}$ and $m_{4}$ will be negative. Including $m_{3}$ and $m_{4}$ to Equation (1) with $z=x$, yields Equation (17) and Equation (18), the components of the utility function of the risk-taking trader,

$$
\begin{aligned}
& P(x)=m_{3} *\left[\left(1-x^{2}\right) d^{2} w / d x^{2}-2 x d w / d x+\left[v(v+1)-\mu^{2} /\left(1-x^{2}\right)\right] w\right] \\
& P(x)=m_{4} *\left[\left(1-x^{2}\right) d^{2} w / d x^{2}-2 x d w / d x+\left[v(v+1)-\mu^{2} /\left(1-x^{2}\right)\right] w\right]
\end{aligned}
$$

As $m_{3}>m_{4}$, the displacement of bitcoin by ether slows over time, we may recast $m_{3}=k($ constant $)+m_{4}$, and adding Equation (17) and Equation (18), as they are the utility functions of a single investor,

$$
\begin{aligned}
& \left(k+m_{4}\right) *\left[\left(1-x^{2}\right) d^{2} w / d x^{2}-2 x d w / d x+\left[v(v+1)-\mu^{2} /\left(1-x^{2}\right)\right] w\right] \\
& +m_{4} *\left[\left(1-x^{2}\right) d^{2} w / d x^{2}-2 x d w / d x+\left[v(v+1)-\mu^{2} /\left(1-x^{2}\right)\right] w\right]
\end{aligned}
$$

Given that ether is a substitute, price expectations may be lower for ether than bitcoin, so the price function may yield the optimal least favorable solution. This price process [27], is given in Equation (20),

$$
P(x)=b_{t}+\int_{0}^{t} x N d x d s+\int_{x>1}^{\infty} x v(d x)(d s)
$$

Where $N(d s, d x)$ is a Poisson process, while $v$ is a constant. We designate $\mathrm{x}>$ 1 , as the price of ether, subject to large jump discontinuities. The unknown nature of future ether paths suggests excessive uncertainty about future prices, or large jump discontinuities. We equate Equation (19) and Equation (20),

$$
\begin{aligned}
& \left(k+m_{4}\right) *\left[\left(1-x^{2}\right) d^{2} w / d x^{2}-2 x d w / d x+\left[v(v+1)-\mu^{2} /\left(1-x^{2}\right)\right] w\right] \\
& +m_{4} *\left[\left(1-x^{2}\right) d^{2} w / d x^{2}-2 x d w / d x+\left[v(v+1)-\mu^{2} /\left(1-x^{2}\right)\right] w\right] \\
& =b_{t}+\int_{0}^{t} \int_{x>1}^{t} x N(d x, d s)+\int_{0}^{t} \int_{x>1}^{t} x v(d x)(d s)
\end{aligned}
$$

The first differential of Equation (21) yields the necessary condition for maximization of risk-taking trader gain, $(S-P)$, (sales price - purchase price of ether),

$$
\begin{aligned}
& (S-P) * m_{4}^{\prime} *\left[(-2 x) d^{3} w / d x^{3}-2 x d^{2} w / d x^{2}+\left[v(v+1)+\mu^{2} /(2 x)\right] w\right] \\
& +m_{4}^{\prime} *\left[(-2 x) d^{3} w / d x^{3}-2 d^{2} w / d x^{2}+\left[v(v+1)+\mu^{2} /(2 x)\right] w\right]=x N+x v
\end{aligned}
$$

The second differential of Equation (21) yields the sufficient condition for the maximization of this trader's gain,

$$
\begin{aligned}
& (S-P) * m_{4}^{\prime \prime} *\left[(-2) d^{4} w / d x^{4}-2 d^{3} w / d x^{3}+\left[v(v+1)+\mu^{2} / 2\right] w\right] \\
& +m_{4}^{\prime \prime} *\left[-2 d^{4} w / d x^{4}-2 d^{3} w / d x^{3}+\left[v(v+1)+\mu^{2} / 2\right] w\right]=N+v
\end{aligned}
$$


Risk-averse traders will invest in ether, if they feel that their investment in bitcoin is becoming unprofitable. Therefore, ether will act as a substitute for bitcoin, if the trader's perception of profit, as depicted in Equation (2) for bitcoin declines with respect to the utility of profit for ether, i.e. ether promises higher future gain. In Equation (24), the ratio of profit expectations for ether to bitcoin $=\theta_{1}$ (profit expectations for ether $/ \theta_{2}$ (profit expectations for bitcoin) $>0$,

$$
\begin{aligned}
P(z)= & \left(1-x^{2}\right) d^{2} w / d x^{2}-2 x d w / d x+\left[v(v+1)-\mu^{2} /\left(1-x^{2}\right)\right] w \\
& +\left[m_{4} / 3 m_{3}-1\right] /\left(\theta_{1} / \theta_{2}\right)\left(\theta_{1} / \theta_{2}\right)-2\left(\theta_{1} / \theta_{2}\right)+\left(\theta_{1} / \theta_{2}\right) /\left(\theta_{1} / \theta_{2}\right)\left(\theta_{1} / \theta_{2}\right) \\
& -3\left(\theta_{1} / \theta_{2}\right) /\left[\left(\theta_{1} / \theta_{2}\right)+3\left(\theta_{1} \cdot \theta_{2}^{-1} m_{4} / 3 m_{3}\right)\right] \\
= & N+v
\end{aligned}
$$

Differentiating Equation (24) twice, and equating to the right side of Equation (23),

$$
\begin{aligned}
& (-2) d^{4} w / d x^{4}-2 d^{3} w / d x^{3}+\left[v(v+1)-\mu^{2} /(-2)\right] w \\
& +\left[m_{4}^{\prime \prime} / 3 m_{3}^{\prime \prime}\right] /\left(\theta_{1} / \theta_{2}\right)^{2}-2\left(\theta_{1} / \theta_{2}\right)+\left(\theta_{1} / \theta_{2}\right) /\left(\theta_{1} / \theta_{2}\right)\left(\theta_{1} / \theta_{2}\right) \\
& -3\left(\theta_{1} / \theta_{2}\right) /\left[\left(\theta_{1} / \theta_{2}\right)+3\left(\theta_{1} \cdot \theta_{2}^{-1} m_{4}^{\prime \prime} / 3 m_{3}^{\prime \prime}\right)\right]=N+v
\end{aligned}
$$

The gain to the risk-averse trader is,

$$
\begin{aligned}
& (S-P) *(-2) d^{4} w / d x^{4}-2 d^{3} w / d x^{3}+\left[v(v+1)-\mu^{2} /(-2)\right] w \\
& +\left[m_{4}^{\prime \prime} / 3 m_{3}^{\prime \prime}\right] /\left(\theta_{1} / \theta_{2}\right)^{2}-2\left(\theta_{1} / \theta_{2}\right)+\left(\theta_{1} / \theta_{2}\right) /\left(\theta_{1} / \theta_{2}\right)\left(\theta_{1} / \theta_{2}\right) \\
& -3\left(\theta_{1} / \theta_{2}\right) /\left[\left(\theta_{1} / \theta_{2}\right)+3\left(\theta_{1} \cdot \theta_{2}^{-1} m_{4}^{\prime \prime} / 3 m_{3}^{\prime \prime}\right)\right]=N+v
\end{aligned}
$$

Figure 2 specifies that informed traders will choose ether if the slope of $O S$, the utility function for ether, is steeper than the slope of $P Q$, the utility function for bitcoin.

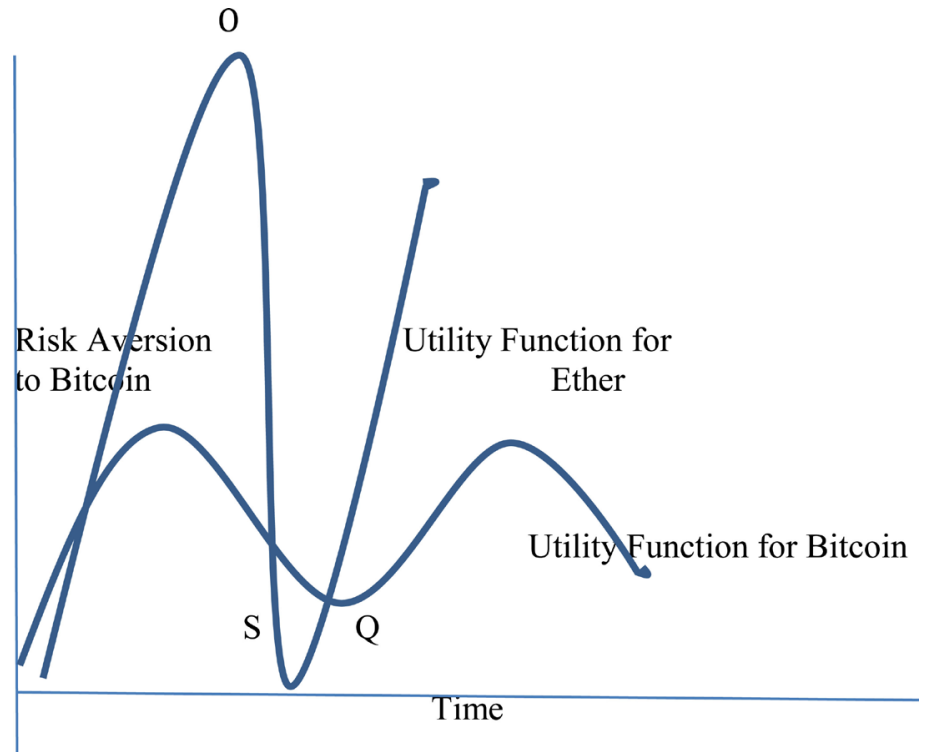

Figure 2. Relative Risk Aversion for Ether and Bitcoin. 


\section{Multiple-Asset Capital Market Line Portfolios}

[12] combined risk-free securities with risky stocks, to create diversified portfolios that minimize variance, and increase return, on the Capital Market Line. The objective of the Capital Market Line is to minimize risk, with the optimal portfolio being the market portfolio of all risky assets. We assume that the diversification of the Capital Market Line reduces the risk of portfolios lying on the Line, to the extent that they meet the risk preferences of risk-averse investors. We exclude risk-takers, who are unlikely to select these portfolios, given their practice of disregarding risk.

If we add bitcoin to a portfolio lying on the Capital Market Line, both the volatility and returns will rise substantially. While the increase in return is attractive, the excessive volatility violates the minimum variance objective of the portfolio. Possible solutions include: 1) Increasing the proportion of the risk-free asset, whose reduced volatility will partly offset the heightened volatility of bitcoin. 2) Short selling the risky asset to reduce volatility, will result in less reduction of returns, than increasing the risk-free asset. The drawback is that high borrowing costs may limit the volume of short selling. 3) Adding foreign currencies, such as the Australian dollar, the British pound, and the euro, reduces covariance risk, as bitcoin has low correlations with these currencies.

The Increased Risk-Free Asset Portfolio. [12] presented the minimum variance portfolio of the risk-free asset and the risky asset as follows, with the objective of minimizing risk, $\Sigma$, while maintaining returns, $m$, above a threshold return, $\mu_{b}$.

$$
\text { Minimize } .5 w^{\mathrm{T}} \Sigma w
$$

Subject to,

$$
m^{\mathrm{T}} w \geq \mu_{b} \text { and } e^{\mathrm{T}} w=1
$$

where, $e$ is a vector of 1 values. The necessary and sufficient conditions for optimality are,

$$
\begin{gathered}
0=\Sigma w-\phi m-\gamma e \\
\mu_{b} \leq m^{\mathrm{T}} w, e^{\mathrm{T}} w=1 \\
\phi\left(m^{\mathrm{T}}-\mu_{b}\right)=0
\end{gathered}
$$

$W=$ weights of assets,

$m=$ return on assets,

$\Sigma=$ covariance risk of the portfolio.

We increase the weight of the riskless asset, and include the cryptocurrency. The objective function becomes,

$$
\text { Minimize } 1 / 2\left(w_{1}+w_{2}+w_{3}+w_{4}\right) * \Sigma^{\prime} w
$$

where, $w_{1}, w_{2}, w_{3}$, and $w_{4}$ are the weights of riskless asset, risky asset, bitcoin, and the additional riskless asset.

$\Sigma^{\prime}$ is the first derivative of the covariance risk, so that the change in cova- 
riance risk, $\Sigma^{\prime}>0$. Assuming a sufficient quantity of riskless assets are added, the covariance risk could be minimized with $\Sigma^{-1}$ multiplying $\Sigma^{\prime}$ to yield $\Sigma$, the covariance risk before the addition of bitcoin. The new optimal objective function becomes,

$$
\text { Minimize } 1 / 2\left(w_{1}+w_{2}+w_{3}+w_{4}\right) * \Sigma w
$$

Yet, as the reduced return of the new portfolio, fails to meet the threshold return.

$\mu_{b}$, we cannot prove that $m^{T} w$ is positive definite,

$$
m^{\mathrm{T}} * \text { symmetric matrix }=a^{*} a+a^{*} b+b^{*} a+b^{*} b
$$

This result $=0$, when $a^{*}$ and $b^{*}$ are 0 , which occurs when $\phi\left(m^{\mathrm{T}}-\mu_{b}\right)=0$ or $\phi=1$. Since $m^{\mathrm{T}}<\mu_{b}, m^{\mathrm{T}} w$, cannot be positive definite, the Capital Market Line portfolio of risk-free asset, risky asset, and bitcoin, cannot achieve minimum risk with maximum return.

Short Selling the Risky Asset. The linear programming model to be minimized,

$\operatorname{Minimize}\left(w_{2} \sigma^{2} x_{2}+w_{3} \sigma^{2} x_{3}+2 w_{1} w_{2} \sigma^{2} x_{2} \sigma^{2} x_{3} \rho x_{2} x_{3}+S K x_{3}+K x_{3}-0.4 \sigma^{2} x_{2}\right)$

Subject to,

$$
w_{1} r_{1}+w_{2} r_{2}+w_{3} r_{3} \geq \mu_{b}
$$

where $\sigma^{2} X_{1}$, the variance of the risk-free asset $=0$,

$W_{1}=$ weight of the risk-free asset,

$W_{2}=$ weight of the risky asset,

$w_{3}=$ weight of bitcoin,

$\mu_{b}=$ the return of a portfolio of the risk-free asset, the risky asset, and bitcoin,

$\sigma^{2} x_{2}=$ the variance of the risky asset,

$\sigma^{2} x_{3}=$ the variance of bitcoin,

$\rho_{x_{1} x_{2}}=$ the correlation coefficient of the risky asset and bitcoin,

$S K_{3}=$ skewness of bitcoin,

$K x_{3}=$ kurtosis of bitcoin,

$-0.4 \sigma^{2} x_{2}=40 \%$ of the risky asset that is short sold,

We assume that skewness and kurtosis are only on bitcoin, and that there is a correlation coefficient of -0.9 , between bitcoin and the risky asset. Applying a Lagrangian function with coefficient, $P$, to Equation (35),

$$
\begin{aligned}
& \operatorname{Minimize}\left(0.6 w_{2} \sigma^{2} x_{2}+w_{3} \sigma^{2} x_{3}-1.8 w_{2} w_{3} \sigma^{2} x_{2} \sigma^{2} x_{3}+S K x_{3}+K x_{3}\right) \\
& -P\left(w_{1} r_{1} x_{1}+w_{2} r_{2} x_{2}+w_{3} r_{3} x_{3}-\mu_{b}\right)
\end{aligned}
$$

$0.6 w_{2} \sigma^{2} x_{2}=60 \%$ of the risky asset that remains in the portfolio, $1.8 w_{2} w_{3} \sigma^{2} x_{2} \sigma^{2} x_{3}=$ twice the correlation coefficient of bitcoin with the risky asset, [27] provides a minimal variance martingale measure, which may be equated to Expression (36),

$$
=2 L_{t}^{2}-\int_{-\infty}^{\infty}\left(e^{2 g}-1\right) N(d t, d x)+L_{t}^{2}\left(f_{t}^{2}+\int_{-\infty}^{\infty}\left(e^{g(t, x)}-1\right)^{2} v d x\right) d t
$$


where,

$$
\begin{aligned}
& L_{t}=\text { a martingale process, } \\
& (g, s) \text { and } f(t, x)=\text { predictable processes, } \\
& N=\text { Poisson process, } \\
& V=\text { a constant. }
\end{aligned}
$$

The necessary condition for minimization is the first derivative of Equation (36), and Equation (37),

$$
\begin{aligned}
& 1.2 w_{2} \sigma x_{2}+2 w_{3} \sigma x_{3}-7.2 w_{2} w_{3} \sigma x_{2} \sigma x_{3}+3 \sigma^{2} x_{3}+4 \sigma^{3} x_{3}-P\left(w_{1} r_{1}+w_{2} r_{2}+w_{3} r_{3}\right) \\
& =4 L_{t}-\left(e^{2 g}\right)\left(N^{\prime}(d t, d t)\right)+2 L_{t}\left(\left(e^{g(t, x)}\right)^{2} v(d x)\right) d t
\end{aligned}
$$

The sufficient condition for minimization is the derivative of Equation (38),

$$
\begin{aligned}
& 1.2 w_{2}\left(1-\mu_{2}\right) \cdot n^{-1}+2 w_{3}\left(1-\mu_{3}\right) \cdot n^{-1}-7.2 w_{2} w_{3}\left(1-\mu_{2}\right) \cdot n^{-1}\left(1-\mu_{3}\right) \cdot n^{-1} \\
& +6 \sigma x_{3}+12 \sigma x_{3}-P\left(w_{1}^{\prime} r_{1}+w_{2}^{\prime} r_{2}+w_{3}^{\prime} r_{3}+w_{4}^{\prime} r_{4}-\mu_{b}\right) \\
& =4 L_{t}^{\prime}-\left(\left(e^{2 g} N^{\prime \prime}(d t, d x)\right)\right)+2 L_{t}^{\prime}\left(\left(e^{g(t, x)}\right) v d x\right) d t
\end{aligned}
$$

Adding Foreign Currencies. Figure 3 depicts three Capital Market Line $(C M L)$ portfolios. The optimal market portfolio of risk-free assets, and risky assets intersects the $C M L$ at $P$. The original lending portfolio, $S$, becomes a borrowing portfolio with the addition of cryptocurrency. 1) With the increase in risk-free assets, the lowest return portfolio, $U$, results, 2) With the short selling of risky assets, the next highest return portfolio, $F$, results, and 3) With the addition of foreign currencies, the highest return portfolio, $G$, is obtained.

In Figure 3, the optimal market portfolio of risk-free assets, and risky assets intersects the $C M L$ at $P$. The original lending portfolio, $S$, becomes a borrowing portfolio at $U$. Among the borrowing portfolios, 1) The increase in risk-free assets yields the lowest-return portfolio, $U, 2)$ The short selling of risky assets creates the next highest return portfolio, $F$, and 3) The addition of foreign currencies yields the highest return portfolio, $G$.

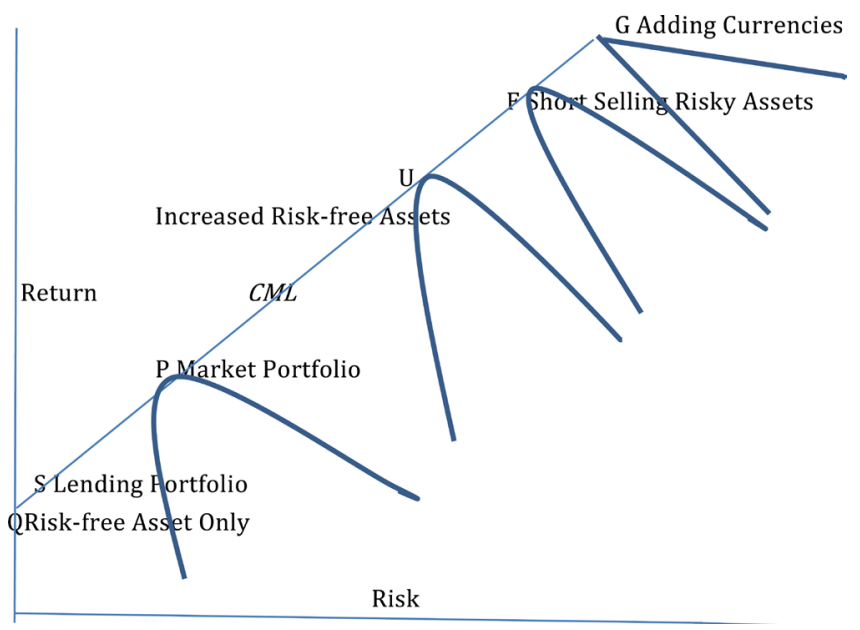

Source: This Paper.

Figure 3. $C M L$ Portfolios of Risk-free Assets, Risky Assets, and Cryptocurrency. 


$$
\begin{aligned}
& \text { Minimize } w_{2} \sigma^{2} x_{2}+w_{3} \sigma^{2} x_{3}+w_{4} \sigma^{2} x_{4}+w_{5} \sigma^{2} x_{5}+2 w_{2} w_{3} \sigma^{2} x_{2} \sigma^{2} x_{3} \rho x_{2} x_{3} \\
& +2 w_{2} w_{4} \sigma^{2} x_{2} \sigma^{2} x_{4} \rho x_{2} x_{4}+2 w_{2} w_{5} \sigma^{2} x_{2} \sigma^{2} x_{5} \rho x_{2} x_{5}+2 w_{3} w_{4} \sigma^{2} x_{3} \sigma^{2} x_{4} \rho x_{3} x_{4} \\
& +2 w_{3} w_{5} \sigma^{2} x_{3} \sigma^{2} x_{5} \rho x_{3} x_{5}+2 w_{4} w_{5} \sigma^{2} x_{4} \sigma^{2} x_{5} \rho x_{4} x_{5}+\sum S k x=3 \text { to } 5 \\
& +\sum K x=3 \text { to } 5-P\left(w_{1} r_{1} x_{1}+w_{2} r_{2} x_{2}+w_{3} r_{3} x_{3}+w_{4} r_{4} x_{4}+w_{5} r_{5} x_{5}-\mu_{b}\right)
\end{aligned}
$$

where,

$$
\begin{aligned}
& x_{1}=\text { the risk-free asset, } \\
& x_{2}=\text { the risky asset, } \\
& x_{3}=\text { the first foreign currency, } \\
& x_{4}=\text { the second foreign currency, } \\
& x_{5}=\text { bitcoin, }
\end{aligned}
$$

We assume positive correlation coefficients of +1 , between 1 ) the risky asset, and the first foreign currency, 2) the risky asset, and the second foreign currency, and 3) the risky asset and bitcoin. Negative correlations of -1 are assumed between 1) the 2 foreign currencies, 2) the first foreign currency and bitcoin, and 3) the second foreign currency and bitcoin. The three positive measures of covariance risk exactly offset the three negative measures of covariance risk, resulting in the minimum variance portfolio, shown in Equation (41),

$$
\begin{aligned}
& \text { Minimize } w_{2} \sigma^{2} x_{2}+w_{3} \sigma^{2} x_{3}+w_{4} \sigma^{2} x_{4}+w_{5} \sigma^{2} x_{5}+2 w_{2} w_{3} \sigma^{2} x_{2} \sigma^{2} x_{3} \\
& +2 w_{2} w_{4} \sigma^{2} x_{2} \sigma^{2} x_{4}+2 w_{2} w_{5} \sigma^{2} x_{2} \sigma^{2} x_{5}-2 w_{3} w_{4} \sigma^{2} x_{3} \sigma^{2} x_{4}-2 w_{3} w_{5} \sigma^{2} x_{3} \sigma^{2} x_{5} \\
& -2 w_{4} w_{5} \sigma^{2} x_{4} \sigma^{2} x_{5}+\sum S k x=3 \text { to } 5 x_{4} / n \sum K x=3 \text { to } 5 \\
& -P\left(w_{1} r_{1} x_{1}+w_{2} r_{2} x_{2}+w_{3} r_{3} x_{3}+w_{4} r_{4} x_{4}+w_{5} r_{5} x_{5}-\mu_{b}\right)
\end{aligned}
$$

The necessary condition for optimization is obtained by differentiating Equation (41) and equating to the right side of Equation (38), given the assumption of a minimal distance martingale measure for the price process,

$$
\begin{aligned}
& 2 w_{2} \sigma x_{2}+2 w_{3} \sigma x_{3}+2 w_{4} \sigma x_{4}+2 w_{5} \sigma x_{5}+8 w_{2} w_{3} \sigma x_{2} \sigma x_{3}+8 w_{2} w_{4} \sigma x_{2} \sigma x_{4} \\
& +8 w_{2} w_{5} \sigma x_{2} \sigma x_{5}-8 w_{3} w_{4} \sigma x_{3} \sigma x_{4}-8 w_{3} w_{5} \sigma x_{3} \sigma x_{5}-8 w_{4} w_{5} \sigma x_{4} \sigma x_{5} \\
& +3\left(\sigma^{2} x_{3}+\sigma^{2} x_{4}+\sigma^{2} x_{5}\right)+4\left(\sigma^{3} x_{3}+\sigma^{3} x_{4}+\sigma^{3} x_{5}\right) \\
& -P\left(w_{1} r_{1}+w_{2} r_{2}+w_{3} r_{3}+w_{4} r_{4}+w_{5} r_{5}\right) \\
& =4 L_{t}-\left(\left(e^{2 g}\right) N d t d x\right)+2 L_{t}\left(\left(e^{g(t, x)}\right)^{2} v d x\right) d t
\end{aligned}
$$

The sufficient condition is obtained by differentiating Equation (42),

$$
\begin{aligned}
& 2 w_{2}\left(1-\mu_{2}\right) \cdot n^{-1}+2 w_{3}\left(1-\mu_{3}\right) \cdot n^{-1}+2 w_{4}\left(1-\mu_{4}\right) \cdot n^{-1}+2 w_{5}\left(1-\mu_{5}\right) \cdot n^{-1} \\
& +8 w_{2} w_{3}\left(1-\mu_{2}\right) \cdot n^{-1}\left(1-\mu_{3}\right)+8 w_{2} w_{4} n^{-1}\left(1-\mu_{2}\right)\left(1-\mu_{4}\right) n^{-1} \\
& +8 w_{2} w_{5} \cdot n^{-1}\left(1-\mu_{2}\right)\left(1-\mu_{5}\right) n^{-1}-8 w_{3} w_{4}\left(1-\mu_{3}\right) \cdot n^{-1}\left(1-\mu_{4}\right) \cdot n^{-1} \\
& -8 w_{3} w_{5}\left(1-\mu_{3}\right) \cdot n^{-1}\left(1-\mu_{5}\right) n^{-1}-8 w_{4} w_{5}\left(1-\mu_{4}\right) n^{-1}\left(1-\mu_{5}\right) n^{-1} \\
& \left.+6\left(\sum \sigma_{x}=3 \text { to } 5\right)+12 \sum \sigma^{3}=3 \text { to } 5\right) \\
& =4 L_{t}^{\prime}-\left(e^{2 g} N^{\prime \prime}(d t, d x)\right)+2 L_{t}^{\prime}\left(\left(e^{g(t, x)}\right) v d x\right) d t
\end{aligned}
$$

Only the Capital Market Line (henceforth, $C M L$ ) with foreign currencies, described by Equation (43), reduces the risk of bitcoin sufficiently, to achieve 
minimum variance, with maximum return. The $C M L$ portfolio with additional risk-free assets, has lower return, while the $C M L$ portfolio that short sells the risky asset, may have excessive risk. Will similar theoretical formulations result from $C M L$ portfolios with other cryptocurrencies? Litecoin and peercoin are so similar to bitcoin, that they may not be expected to differ from bitcoin. Yet, there is no literature that describes its correlations with securities, or foreign currencies. Therefore, ether has greater uncertainty of price expectations, with similar returns. To construct a minimum variance portfolio for ether, we add an additional stable foreign currency, such as the euro, which is constrained to a strict band by the regulations of the European Monetary System, or the Australian dollar, or the New Zealand dollar ([30]. We repeat Equation (42), including the euro, the Australian dollar, or the New Zealand dollar, as the sixth portfolio asset. The sixth asset has a correlation coefficient of +1 , with each foreign currency, and a correlation coefficient of -1 , with bitcoin. The necessary condition for optimization is,

$$
\begin{aligned}
& 2 w_{2} \sigma x_{2}+2 w_{3} \sigma x_{3}+2 w_{4} \sigma x_{4}+2 w_{5} \sigma x_{5}+2 w_{6} \sigma x_{6}+8 w_{2} w_{3} \sigma x_{2} \sigma x_{3} \\
& +8 w_{2} w_{4} \sigma x_{2} \sigma x_{4}+8 w_{2} w_{5} \sigma x_{2} \sigma x_{5}+8 w_{2} w_{6} \sigma x_{2} \sigma x_{6}-8 w_{3} w_{4} \sigma x_{3} \sigma x_{4} \\
& -8 w_{3} w_{5} \sigma x_{3} \sigma x_{5}-8 w_{4} w_{5} \sigma x_{4} \sigma x_{5}-8 w_{5} w_{6} \sigma x_{5} \sigma x_{6}+3\left(\sigma^{2} x_{3}+\sigma^{2} x_{4}+\sigma^{2} x_{5}\right. \\
& \left.+\sigma^{2} x_{6}+\sum S K x=3 \text { to } 6\right)-P\left(w_{1} r_{1}+w_{2} r_{2}+w_{3} r_{3}+w_{4} r_{4}+w_{5} r_{5}+w_{6} r_{6}\right) \\
& =4 L_{t}-\left(\left(e^{2 g}\right) N(d t, d x)\right)+2 L_{t}\left(e^{g(t, x)}\right)^{2} v d x d t
\end{aligned}
$$

The sufficient condition is obtained by differentiating Equation (44),

$$
\begin{aligned}
& 2 w_{2}\left(1-\mu_{2}\right) \cdot n^{-1}+2 w_{3}\left(1-\mu_{3}\right) \cdot n^{-1}+2 w_{4}\left(1-\mu_{4}\right) \cdot n^{-1}+2 w_{5}\left(1-\mu_{5}\right) \cdot n^{-1} \\
& +2 w_{6}\left(1-\mu_{6}\right) \cdot n^{-1}+8 w_{2} w_{3}\left(1-\mu_{2}\right) \cdot n^{-1}\left(1-\mu_{3}\right) \cdot n^{-1} \\
& +8 w_{2} w_{4}\left(1-\mu_{2}\right) \cdot n^{-1}\left(1-\mu_{4}\right) \cdot n^{-1}+8 w_{2} w_{5}\left(1-\mu_{2}\right) \cdot n^{-1}\left(1-\mu_{5}\right) \cdot n^{-1} \\
& +8 w_{2} w_{6}\left(1-\mu_{2}\right) \cdot n^{-1}\left(1-\mu_{6}\right) n^{-1}-8 w_{3} w_{4}\left(1-\mu_{3}\right) \cdot n^{-1} \cdot\left(1-\mu_{4}\right) \cdot n^{-1} \\
& +8 w_{3} w_{5}\left(1-\mu_{3}\right) \cdot n^{-1}\left(1-\mu_{5}\right) \cdot n^{-1}-8 w_{4} w_{5}\left(1-\mu_{4}\right) \cdot n^{-1}\left(1-\mu_{5}\right) \cdot n^{-1} \\
& -8 w_{5} w_{6}\left(1-\mu_{5}\right) \cdot n^{-1}\left(1-\mu_{6}\right) \cdot n^{-1}+6\left(\sigma x_{3}+\sigma x_{4}+\sigma x_{5}+\sigma x_{6}\right. \\
& +\left(\sum x=3 \text { to } 6\right)\left(2 \sigma^{2} x+1.5 \sigma^{3} x\right)-P\left(w_{1} r_{1}^{\prime \prime}+w_{2} r_{2}^{\prime \prime}+w_{3} r_{3}^{\prime \prime}+w_{4} r_{4}^{\prime \prime}+w_{5} r_{5}^{\prime \prime}+w_{6} r_{6}^{\prime \prime}\right) \\
& =4 L_{t}^{\prime}-\left(e^{2 g} N^{\prime} d t d x\right)+2 L_{t}^{\prime}\left(e^{g(t, x)}\right)^{2} v d x d t
\end{aligned}
$$

The drawback of the $C M L$ portfolio, is its employment of the riskless asset. The reduction in risk may only be achieved by reducing returns. This reduction of returns is exacerbated with the strategy of short selling the risky asset. It may be concluded that an optimal cryptocurrency portfolio should be broadly diversified to reduce portfolio risk, without the reduction in returns of the riskless asset.

The Proposed Multiple-Asset Cryptocurrency Portfolio. We assume that risk-averse traders will pursue one of the aforementioned $C M L$ portfolio strategies. For the risk-taker, we take 1)risky stock underlying equity options, 2) bitcoins, which has volatile prices, 3) US dollars, with relatively stable prices, 4) 
soybean futures, 5) Treasury bond futures, that rise with declines in bitcoin, or currency options on volatile Mexican pesos 6) risky technology and biotechnology stocks, 7) cyclical oil futures, 8) relatively stable currency call options on US dollars, and 9) and highly volatile currency call options on Mexican peso. This combination of assets has high returns above the CML. This is in accordance with [5]'s 13-asset portfolio, though that portfolio was less successful in controlling risk. This paper's proposed portfolio contains assets with correlation coefficients of zero with other assets, which reduce covariance risk of the portfolio. Equating the Legendre utility function for risk-takers, with the price function of the aforementioned 9 assets,

$$
\begin{aligned}
& \left(1-z^{2}\right) d^{2} x / d z^{2} z d w / d z+\left[v(v+1)-\mu_{1}^{2} /\left(1-z^{2}\right)\right] w \\
& =\left(1 / x_{1} \sigma_{1} \sqrt{2} \Pi\right) e^{\left(\ln x_{1}-\mu_{1}\right)^{2}} / 2 \sigma_{1}^{2}+Z_{t} b+t \int_{0}^{t}\left(e^{x 2}-1-x_{2}\left(\left|x_{2}\right| \leq 1\right)\left(x_{2}\right)\right) v d x \\
& +\int_{0}^{t} \int_{x<1}^{\infty}\left(e^{x 2}-1\right) N d s d x+L\left[\left(x_{2}-\mu_{2}\right)^{2} / \sigma_{2}+\left(x_{2}-\mu_{2}\right)^{3} / \sigma_{2}\right. \\
& \left.+\left(x_{2}-\mu_{2}\right)^{4} / \sigma_{2}\right]+\partial t p\left(x_{3}, t\right)+\Pi \theta x \partial x_{3}^{2} \sigma_{3}\left(x_{3}, t\right)^{2} / 2 \cdot p\left(x_{3}, t\right) \\
& +Y_{4}-a_{4} b_{4}+Y_{5}-a_{5} b_{5}+\left(1 / x_{6} \sigma_{6} \sqrt{2} \Pi\right) e^{-\left(\ln x_{6}-\mu_{6}\right)^{2}} \cdot 5 \sigma_{6}^{2} \\
& +1 / \sqrt{2} \Pi \sigma_{7}^{2} \exp ^{-\left(x_{7}-\mu_{7}\right)} / 2 \sigma_{7}^{2}+\int e i \theta x_{8 t} I|x<1| \Pi d x+\int e i \theta x_{9 t} I|x>1| \Pi d x
\end{aligned}
$$

where,

$x_{1}=$ risky stock underlying equity options, following a lognormal distribution, with probability density function ([31]),

$x_{2}=$ bitcoin value, whose distribution is represented by Equation (6) of this paper,

$x_{3}=$ US dollar value, the Fokker-Planck equation with US dollar value,

with currency values based on changes in macroeconomic variables, including inflation, short-term interest rates, long-term interest rates, government debt, export prices, import prices, and political stability.

$x_{4}=$ soybean futures, $Y_{4}=a_{4}+b_{4} x_{4}$

$x_{5}=$ Treasury bond futures, $Y_{5}=a_{5}+b_{5} x_{5}$

$x_{6}=$ technology/biotechnology stocks, following a lognormal distribution,

$x_{7}=$ oil futures values, described by a continuous normal distribution to capture the cyclical nature of oil prices,

$x_{8}=$ currency options on US dollars, Levy-Khintchine distribution of a currency call option with small jumps,

$x_{9}=$ currency options on Mexican pesos, Levy-Khintchine distribution for a currency call option with large jumps,

The necessary condition for the optimization of portfolio risk and return is obtained by differentiating Equation (46). If $w=$ the coefficient of relative risk aversion, the relative risk aversion across 9 assets cancels out, resulting in $d w / d x$ $=0$, or the left side reducing to $\mu^{2} w / 2 x$. The first derivative of Equation (46) is given below, 


$$
\begin{aligned}
& \mu^{2} w / 2 x \\
& =(1 / \sqrt{2} \Pi) e^{\wedge}\left(\ln x_{1}-\mu_{1}\right)^{2} \sigma^{2} / 2+Z_{t} b+t\left(e^{x 2}-1-x_{2}\left(\left|x_{2}\right| \leq 1\right)\left(x_{2}\right)\right) v \\
& +\int_{x<1}^{\infty}\left(e^{x 2}-1\right) N_{p} d s d x+L^{\prime}\left[\left(x_{2}-\mu_{2}\right)^{2} / \sigma_{2}+\left(x_{2}-\mu_{2}\right)^{3} / \sigma_{2}\right. \\
& \left.+\left(x_{2}-\mu_{2}\right)^{4} / \sigma_{2}\right]+\partial^{\prime} t p\left(x_{3}, t\right)+d y_{4} / d x_{4}-a_{4} d^{2} y_{4} / d x_{4}^{2}+d y_{5} / d x_{5} \\
& +a_{5} d^{2} y_{5} / d x_{5}^{2}+(1 / \sqrt{2} \Pi) e^{\wedge}-\left(\ln x_{6}-\mu_{6}\right)^{2} \sigma_{6}^{2} / 2 \\
& -\left[\left[\left(x_{7}-\mu_{7}\right) / 2 \sigma_{7}^{2}\right] \exp -\left(x_{7}-\mu_{7}\right)-1\right] \\
& +\left(e i \theta x_{8 t}-1-i \theta x_{8 t} I|x<1|\right) \Pi+\left(e i \theta_{8 t}-1-i \theta x_{9 t} I|x<1|\right) \Pi
\end{aligned}
$$

The sufficient condition for optimization is the second derivative of Equation (46), given below. We add the gradient vector to reduce volatility, and the Laplace transform to reduce skewness and kurtosis.

$$
\begin{aligned}
& \mu^{2} w / 2 \\
& =(1 / \sqrt{2} \Pi) e^{\wedge}\left(\ln x_{1}-\mu_{1}\right)^{2} \sigma^{2} / 2+\left(e^{x 2}\left(\left|x_{2}\right| \leq 1\right) x_{2}\right) v \\
& +\left(e^{x 2}-1\right) N_{p}+L^{\prime \prime}\left[\left(x_{2}-\mu_{2}\right)^{2} / \sigma_{2}+\left(x_{2}-\mu_{2}\right)^{3} / \sigma_{2}\right. \\
& \left.-\left(x_{2}-\mu_{2}\right)^{4} / \sigma_{2}\right]+\partial^{\prime \prime} t p\left(x_{3}, t\right)+2 \Pi \theta x \partial^{4} x_{3} / d x^{4}\left(x_{3}, t\right) p\left(x_{3}, t\right) \\
& +d^{2} y_{4} / d y_{4}^{2}-a_{4} d^{3} y_{4} / d x_{4}^{3}+d^{2} y_{5} / d x_{5}^{2} \\
& +(1 / \sqrt{2} \Pi) e^{\wedge}-\left(\ln x_{6}-\mu_{6}\right)^{2} \sigma_{6}^{2} / 2 \\
& -\sqrt{2\left[1-\mu_{7}\right]} / 4 \sigma_{7}\left(\Pi \sigma_{7}\right)\left(x_{7}-\mu_{7 ?}-1\right)\left(x_{7}-\mu_{7}\right) \\
& +\left(e i \theta x_{8 t}-i \theta x_{8 t} I|x<1|\right) \Pi+\left(e i \theta_{8 t}-i \theta x_{9 t} I|x<1|\right) \Pi \\
& +\nabla_{g 1}^{2}+L(s, x) \sum S K x=2 \text { to } 9+L \sum K_{x}=2 \text { to } 9
\end{aligned}
$$

where,

$S k=$ skewness of bitcoin, foreign currency, technology stock, and currency options,

$K x=$ kurtosis of bitcoin, foreign currency, technology stock, and currency options,

$\nabla_{g q}^{2}=$ gradient vectors to suppress stock volatility,

$L(s, x)=$ Laplace transforms to suppress skewness and kurtosis.

\section{Conclusions}

This paper is the first attempt to create a theoretical portfolio containing cryptocurrencies, either as a single asset, or as part of a multiple-asset portfolio, within the framework of modern portfolio theory. As a single asset, the cryptocurrency may be retained, by either risk-taking informed traders, or risk-averse informed traders, who base its value on the beneficial impact of recording transactions on the blockchain, without the services of intermediaries, such as banks. Two of the $C M L$ portfolios of increasing the proportion of riskless assets, or short selling risky assets, failed to achieve minimum risk. Only the $C M L$ portfolio with foreign currencies, mitigated the excessive risk of the cryptocurrency, 
suggesting the need for the inclusion of negatively correlated, or uncorrelated, assets. The proposed portfolio consists of 9 assets, which are predominantly uncorrelated with each other, or are uncorrelated with the cryptocurrency, to reduce risk. As cryptocurrencies are deflationary, we recommend the inclusion of a hedge against deflation. One such inflationary asset, is the Treasury bond future. This suggestion contrasts with the [5] portfolio, which did not include such a deflationary hedge, resulting in an unbalanced, deflation-inducing portfolio, with gold, and inflation-indexed Treasury securities.

Both the [5] portfolio, and the [22] portfolios had excessive kurtosis, or fat-tailed distributions. [32] and [33] provide empirical evidence of non-Gaussian cryptocurrency distributions with heavy tail risk. What causes tail risk? The presence of an excessive number of outliers causes cryptocurrency distributions to exhibit significant tail risk. Traditional methods of risk reduction, such as portfolio diversification exacerbate tail risk, as observed in successive studies ([34] [35]) by introducing additional outliers into existing cryptocurrency portfolio distributions. We posit that tail risk reduction may be achieved by eliminating outliers. [33] measured bitcoins extremal index with the US dollar at.55 for 64 runs at run lengths of 3 , as opposed to values of $>0.7$ for similar run lengths for the Australian dollar and Canadian dollar with the US dollar. Trades of bitcoin with extremal index values $<0.6$ with the US dollar should be avoided. [33] measured value-at-risk values for bitcoin/US dollar distributions (historical VAR $=0.055$, Gaussian VAR $=0.068$ ), while the US dollar with a basket of 7 OECD currencies had a mean historical VAR of 0.01, and a mean Gaussian VAR of 0.011143. As historical VARs are identical, and mean Gaussian VARs show substantial difference, mean Gaussian VARs for Bitcoin portfolios with the US dollar must be brought within 1.5 standard deviation of fiat currency portfolios with the US dollar. Also, our portfolios are categorized by the level of risk-aversion of the traders. Eliminating extreme value trades by high risk takers or extreme risk-avoiders will reduce value-at-risk to levels 1.5 times that of G10 currencies. Does this suggest that traditional diversification should not be employed at all? We do not support this position, maintaining that diversification, as in our proposed model may be deployed to reduce overall covariance risk. However, diversification will be ineffective in reducing tail risk, as it does not limit the outliers that cause tail risk. Therefore, diversification must be supplemented with the elimination of outliers. Another method is the addition of volatile currencies, that follow a Laplace distribution. Laplace transforms, may be employed to reduce kurtosis. We suggest that the following currencies be added to a cryptocurrency portfolio. All of them fluctuate considerably, as their economies are commodity-driven, so that the currencies rise and drop sharply, with changes in commodity prices. Political instability, and the removal of capital controls, resulting in capital flight, also contributes to currency destabilization. The currencies include, the Azerbaijani manat, the Kazakhastan tenge, tied to oil prices, the Zambian kwacha, linked to the price of copper, the Belarusian ruble, the Argen- 
tine peso, linked to the end of capital controls, the Brazilian real, related to high inflation, and political instability, the Mozambique metcal, based on the prices of sugar, coal, and cotton, and the Malawian kwacha, based on limited foreign direct investment, based on the prices of sugar, coal, and cotton, and the Malawian kwacha, based on limited foreign direct investment, and high inflation.

The next stage of the theoretical analysis, is to ground cryptocurrency investments within the framework of the Capital Asset Pricing Model, (henceforth, $C A P M$, [8], and the Fama-French models of security valuation. $C A P M$ views the return on a security in terms of market movements. Yet, cryptocurrencies correlate poorly with the market, so that the return on a cryptocurrency cannot be explained by $C A P M$. Consequently, cryptocurrencies are a $C A P M$ anomaly. The [31] model adjusted $C A P M$ for the aberrations in security returns, due to size (small firms were observed to have higher returns, than large firms), book-to-market (high book-to-market firms had higher returns, than low book-to-market firms), and momentum (stocks, with large price increases in the previous period, outperformed their counterparts, without such increases). As cryptocurrencies are not larger, have high book-to-market, or higher momentum, their prices cannot be explained by the Fama-French model. If cryptocurrencies are anomalous in traditional security return models, they may be speculative investments, such as derivatives. While derivatives are supported by the value of stocks for equity options, real estate for real options, or currency, for currency derivatives, cryptocurrencies are supported by belief in the power of the blockchain to reduce transactions costs for businesses. In essence, cryptocurrencies are supported by faith.

For less rational investors, who seek speedy profits, cryptocurrency valuations have taken the form of a bubble, with speculators driving up prices. The extent of rationality in cryptocurrency price-setting, as opposed to bubble-like speculation, may form the basis for future research. Another area of research, is the relationship of cryptocurrencies to gold. Both are hedges against inflation. What is the relationship between them? Should a portfolio contain one, or both? Theoretical and empirical relationships must be explored.

\section{Conflicts of Interest}

The authors declare no conflicts of interest regarding the publication of this paper.

\section{References}

[1] Tepper, F. (2017) What the Hell Is Happening to Cryptocurrency Valuation? Techcrunch, June 7. https://techcrunch.com

[2] Baron, J., O’Mahoney, A., Manheim, D. and Dion-Schwartz, C. (2015) The Current State of Virtual Currencies, National Security Implications of Virtual Currency. Rand Corporation, Los Angeles.

[3] Boehme, R., Chester, N., Edelman, B. and Moore, T. (2015) Bitcoin: Economics, Technology, and Governance. Journal of Economic Perspectives, 29, 213-238. 
https://doi.org/10.1257/jep.29.2.213

[4] Gandal, N. and Halaburda, N. (2014) Competition in the Cryptocurrency Market. The Workshop on the Economics of Information Security, State College, 23 June 2014, 1-32. https://doi.org/10.2139/ssrn.2506463

[5] Brere, M., Oosterlink, K. and Szafarz, A. (2017) Virtual Currency, Tangible Return: Portfolio Diversification with Bitcoin. Working Paper, 13/031, Centre Emile Bernheim, Solvay Brussels School of Economics and Management, Brussels.

[6] Black, F. and Scholes, M. (1973) The Pricing of Options and Corporate Liabilities. Journal of Political Economy, 81, 637-654. https://doi.org/10.1086/260062

[7] Merton, R.C. (1973) An Intertemporal Capital Asset Pricing Model. Econometrica, 41, 867-887. https://doi.org/10.2307/1913811

[8] Sharpe, W.F. (1964) Capital Asset Prices: A Theory of Market Equilibrium under Conditions of Risk. Journal of Finance, 19, 425-442. https://doi.org/10.1111/j.1540-6261.1964.tb02865.x

[9] Feng, W., Wang, Y. and Zhang, Z. (2017) Informed Trading in the Bitcoin Market. Finance Research Letters, 26, 63-70. https://doi.org/10.1016/j.frl.2017.11.009

[10] Ferriani, F. (2010) Informed and Uninformed Traders at Work: Evidence from the French Market. Munich Personal RePec No. 24487, Archive.

[11] Admati, A.R. and Pfleiderer, P. (1988) Markets for Information. American Economic Review, 78, 96-103.

[12] Markowitz, H. (1952) Portfolio Selection. Journal of Finance, 7, 77-99. https://doi.org/10.2307/2975974

[13] Easley, D.O., O’Hara, M. and Srinivas, P. (1998) Option Volume and Stock Prices: Evidence on Where Informed Traders Trade. Journal of Finance, 53, 431-465. https://doi.org/10.1111/0022-1082.194060

[14] Florian, G., Zimmerman, K., Haferkorn, M., Weber, M.C. and Siering, M. (2017) Bitcoin: Asset or Currency? Revealing Users Hidden Intentions. The Twenty-Second European Conference on Information Systems, Tel Aviv, November 2017, 1-14.

[15] Easley, D. and O'Hara, M. (1992) Time and Process of Security Price Adjustment. Journal of Finance, 47, 576-605. https://doi.org/10.1111/j.1540-6261.1992.tb04402.x

[16] Heflin, F. and Shaw, K.W. (2002) Blockholder Ownership and Market Liquidity. Journal of Finance and Quantitative Analysis, 35, 621-633. https://doi.org/10.2307/2676258

[17] Biais, B., Hillion, P. and Spratt, C. (1995) An Empirical Analysis of the Limit Order Book, and Order Flow on the Paris Bourse. Journal of Finance, 50, 1655-1689. https://doi.org/10.1111/j.1540-6261.1995.tb05192.x

[18] Abraham, R., Harrington, C.W. and Williams, A.A. (2011) Multimarket Trading at Merger Announcement and Completion. Journal of Derivatives and Hedge Funds, 17, 186-197. https://doi.org/10.1057/jdhf.2011.13

[19] Kristoufek, L. (2013) Bitcoin Meets Google Trends and Wikipedia: Quantifying The Relationship between Phenomena of the Internet Era. Scientific Reports, 3, Article No. 3415. https://doi.org/10.1038/srep03415

[20] Caian, P., Rajcaniova, M. and Kancs, D.A. (2016) The Economics of Bitcoin Price Formation. Applied Economics, 48, 1799-1815. https://doi.org/10.1080/00036846.2015.1109038

[21] Baek, C. and Elbeck, M. (2017) Bitcoins as an Investment or Speculative Vehicle? A 
First Look. Applied Economics Letters, 1, 30-34. https://doi.org/10.1080/13504851.2014.916379

[22] Hong, K. (2016) Bitcoin as an Alternative Investment Vehicle. Information Technology Management, 18, 265-275. https://doi.org/10.1007/s10799-016-0264-6

[23] Abramowitz, M. and Stegun, I. (1964) Handbook of Mathematical Functions with Formulas, Graphs, and Mathematical Tables (National Bureau of Standards Applied Mathematics Series No. 55). U.S. Government Printing Office, Washington DC. https://doi.org/10.1115/1.3625776

[24] Prakash, A., Chang, C.H. and Hamid, S. (1996) Why a Decision-Maker May Prefer a Seemingly Unfair Gamble. Decision Sciences, 27, 239-253. https://doi.org/10.1111/j.1540-5915.1996.tb01717.x

[25] Abraham, R. (2018) Pricing Currency Call Options. Theoretical Economics Letters, 8, 2271-2289. https://doi.org/10.4236/tel.2018.811148

[26] Esscher, F. (1932) On the Probability Function in the Collective Theory of Risk. Skandinavisk Aktuarietidskrift, 15, 175-195. https://doi.org/10.1080/03461238.1932.10405883

[27] Miyahara, Y. (2012) Option Pricing in Incomplete Markets. Imperial College Press, London. https://doi.org/10.1142/p622

[28] Steadman, I. (2013) Wary of Bitcoin? A Guide to Some Other Cryptocurrencies. Arts Technica, 5, 11.

[29] Torpey, K. (2017) Will Bitcoin's Lightening Network Kill off Altcoins Focused on Cheap Transactions? Forbes, December 28. https://forbes.com/sites/ktorpey

[30] Yeates, C. (2010) Aussie Now Fifth Most Traded Currency. The Sydney Morning Herald.

https://www.smh.com.au/business/aussie-now-fifth-mosttraded-currency20100901 -14-nma.html

[31] Fama, E.F. and French, K.R. (1992) The Cross-Section of Expected Stock Returns. Journal of Finance, 47, 427-465. https://doi.org/10.1111/j.1540-6261.1992.tb04398.x

[32] Chu, J., Chan, S., Nadarajah, S. and Osterrieder, J. (2017) GARCH Modelling of Cryptocurrencies. Journal of Risk and Financial Management, 10, 1-15. https://doi.org/10.3390/jrfm10040017

[33] Osterrieder, J. and Lorenz, J. (2017) A Statistical Risk Assessment of Bitcoin and Its Extreme Tail Behavior. Annual Financial Economics, 12, 1-13. https://doi.org/10.1142/S2010495217500038

[34] Ibragimov, R. and Pokhorov, A. (2016) Heavy Tails and Copulas: Limits of Diversification Revisited. Economics Letters, 149, 102-107. https://doi.org/10.1016/j.econlet.2016.10.024

[35] Gkillas, K., Bekiros, S. and Siriopoulos, C. (2018) Extreme Correlation in Cryptocurrency Markets. SSRN Working Paper Series. http://ssrn.com/abstract=3180934 https://doi.org/10.2139/ssrn.3180934 